\title{
Anne Lise Ellingsaeter, An-Magritt Jensen, Merete Lie (Eds.): The Social Meaning of Children and Fertility Change in Europe
}

\author{
Ivett Szalma
}

Published online: 28 January 2014

(C) Springer Science+Business Media Dordrecht 2014

The chapters in this book examine the questions of why people have children and what children mean to them in a background of prevailing low fertility levels. To this end most of the authors have conducted qualitative research in the form of semistructured interviews, biographical interviews, or using focus groups. The empirical studies examined four comparatively high fertility countries (France, Denmark, Norway and Sweden) and two low fertility countries (Germany and Italy). The book contains nine empirical studies and two overview chapters written by the editors which frame the studies.

In the introductory chapter, the three editors analyse the meaning of children by reviewing changes in fertility levels in Europe and they also provide an overview of the following chapters.

Four chapters focus on the social meaning of children by analysing the direct factors determining the reproductive decision. In the second chapter Marie-Thérèse Letablier discusses the role of policy in the construction of the social meaning of children in a historical perspective in France. Mai Heide Ottosen and Sofie Skvovdal Mouritzen employ a biographical approach-conducting 33 interviews with young women and men in their 20 s and $30 \mathrm{~s}$ - in order to map patterns of partnerships and parenthood in Denmark. Malin Noem Ravn and Merete Lie employ cultural analysis in order to identify whether the decision to bear a child is embedded in the cultural context in Norway. They find that there is a cultural consensus among Norwegians about the decision to have a child and its timing having to be a joint decision. In the following chapter Disa Bergnéhr and Eva Bernhardt analysed the decision of childbearing by focusing on both the negative (restrictions in their freedom) and positive (making sense of their life) meanings associated with childbearing in Sweden combining qualitative survey data with qualitative focus groups interviews.

I. Szalma (ه)

Swiss Centre of Expertise in the Social Sciences (FORS), Lausanne, Switzerland

e-mail: ivett.szalma@unil.ch 
One strong point of the book is that in almost all studies the authors pay attention to the social stratification aspects such as gender, cohort and social classes. Two chapters put a special emphasis on social stratification by gender and social class. In An-Magritt Jensen's paper the gender and class perspective is central. She tries to answer the following paradox: Why are women having more children while more men are remaining childless in Norway? The author relies on qualitative analyses based on 90 semi-structured interviews. She finds that children are not part of life in similar ways for men and for women. Trude Lappegård and her co-authors investigated the changes in fertility patterns related to gender, social class and employment status in Norway. They compared two cohorts that grew up in different societal contexts. The main finding of their study is that the social differences in fertility patterns seem to increase among men but decrease among women.

Three studies specifically examine how the different social contexts such as employment status, social policy and social networks influence decisions on childbearing. Anne Lise Ellingsæter and Eirin Pedersen reveal how the economic risk and welfare state influenced the fertility levels of individuals. Their study is based on 90 interviews with young Norwegians from different social classes who are in the beginning of their fertility careers. The result of their research is that the welfare state can mitigate the economic risk associated with having children. The following study focuses on "blurring boundaries" of work and family life in West and East Germany. Karin Jurczyk conducted 76 interviews with mothers and fathers who work in the retail and the media industries. She finds that flexible work provokes problems of work-life balance. For example, the opening hours of the crèche and kindergarten do not adjust to the changes in flexible working time. Since flexible work is more and more widespread it seems that the social meaning of children is not embedded in the new structure of work. Laura Bernardi examines the intergenerational transmission of fertility norms between mothers and their daughters in Italy. She conducted 36 semi-structured interviews with childless women of reproductive age and their mothers in Italy. She finds an intergenerational pattern in childbearing between mothers and their daughters. This pattern is strongly related to the daughters' experiences of their own mother during childhood and from the way in which their mothers interpreted their own roles as wives and mothers.

In the concluding chapter, the three editors address how these case studies contribute to understand the social meaning of children embedded in social contexts such as micro environments (values and norms and social networks) and macro environments (social policies, labour market and economic security).

One of the limitations of this book is that it does not include papers on the social meaning of children in Eastern Europe, in spite of the fact that significant changes in fertility patterns have recently occurred in that region. Another is that each of the papers concentrates on a single country so the lack of international comparisons clouds a better understanding of the effects of such macro factors. Nevertheless, a major strength of the book is that almost all of the studies reflect how the social meaning of children is embedded in the social contract and the relationship between decisions on childbearing and social stratifications. Despite the family is still the primary channel reproducing social inequalities, it is remarkable that so far only a few studies have paid attention to the role of social stratification in the social 
meaning of children. This volume is therefore to be welcomed as an insightful pioneer in this important field. 